\title{
Extracellular riboflavin induces anaerobic biofilm formation in Shewanella oneidensis
}

\author{
Miriam Edel' ${ }^{1}$, Gunnar Sturm², Katrin Sturm-Richter ${ }^{1}$, Michael Wagner ${ }^{2}$, Julia Novion Ducassou ${ }^{3}$, Yohann Couté3, \\ Harald Horn ${ }^{4,5}$ and Johannes Gescher ${ }^{1,2^{*}}$ (1)
}

\begin{abstract}
Background: Some microorganisms can respire with extracellular electron acceptors using an extended electron transport chain to the cell surface. This process can be applied in bioelectrochemical systems in which the organisms produce an electrical current by respiring with an anode as electron acceptor. These organisms apply flavin molecules as cofactors to facilitate one-electron transfer catalyzed by the terminal reductases and in some cases as endogenous electron shuttles.

Results: In the model organism Shewanella oneidensis, riboflavin production and excretion trigger a specific biofilm formation response that is initiated at a specific threshold concentration, similar to canonical quorum-sensing molecules. Riboflavin-mediated messaging is based on the overexpression of the gene encoding the putrescine decarboxylase speC which leads to posttranscriptional overproduction of proteins involved in biofilm formation. Using a model of growth-dependent riboflavin production under batch and biofilm growth conditions, the number of cells necessary to produce the threshold concentration per time was deduced. Furthermore, our results indicate that specific retention of riboflavin in the biofilm matrix leads to localized concentrations, which by far exceed the necessary threshold value.
\end{abstract}

Conclusion: This study describes a new quorum-sensing mechanism in S. oneidensis. Biofilm formation of S. oneidensis is induced by low concentrations of riboflavin resulting in an upregulation of the ornithine-decarboxylase speC.

The results can be applied for the development of strains catalyzing increased current densities in bioelectrochemical systems.

Keywords: Biofilm, Current density, Shewanella oneidensis, Microbiology, Quorum sensing

\section{Main text \\ Background}

Flavin molecules accelerate extracellular respiratory processes. These processes are specific adaptations used by cells to couple oxidation of an electron donor to respiratory electron transport with insoluble or membraneimpermeable electron acceptors [1]. These reduction processes are of environmental relevance. For instance,

\footnotetext{
*Correspondence: Johannes.gescher@kit.edu

${ }^{1}$ Institute for Applied Biosciences, Department of Applied Biology, Karlsruhe Institute of Technology, Karlsruhe, Germany

Full list of author information is available at the end of the article
}

iron, the fourth most abundant element in the earth crust, occurs in soil and sediments in the form of insoluble iron oxides or oxyhydroxides and is one target for extracellular electron transfer processes. Moreover, reduction of insoluble electron acceptors can be applied in bio-electrochemical systems (BES), in which a solidstate anode is used by the microorganisms as an electron acceptor instead of environmental iron or manganese minerals. Hence, the organisms catalyze in BES the direct conversion of chemical into electrical energy.

Riboflavin and other flavin species are excreted by the $\mathrm{y}$-proteobacterium Shewanella oneidensis, which is a model organism for extracellular electron transfer [2]. 
Extracellular flavins can be used as endogenous electron shuttles by $S$. oneidensis, and it was discovered that the presence of flavins has a positive impact on extracellular respiration kinetics [2-4]. Recently, it was revealed that the influence of flavins is also due to their function as cofactors of the terminal reductases of the organism. As cofactor, riboflavin causes acceleration of the activity of outer membrane cytochromes by facilitating oneelectron transport via the formation of semiquinones [5-7]. Meanwhile, it has become evident that flavins are not only cofactors of outer membrane cytochromes of S. oneidensis, but also of Geobacter sulfurreducens (the other main model organism for extracellular electron transfer processes) $[6,8]$. Furthermore, it was demonstrated that flavo-enzymes are also used as terminal reductases of ferric iron in Gram-positive organisms [9].

Although the excretion of flavins was hypothesized to be of minor relevance regarding necessary energy and carbon source investment [2], it is still unclear why Shewanella strains do not bind flavin molecules as tightly to the outer membrane cytochromes as do Geobacter strains. A release of flavins into the medium supernatant has not been discovered for Geobacter strains so far. As a result of this study, we suggest that riboflavin in addition to its function as cofactor and potential electron shuttle is also a messenger molecule used to facilitate anaerobic biofilm formation in S. oneidensis dependent on the concentration of cells.

Quorum sensing is a microbial process that regulates the initiation of physiological responses in a cell concentration-dependent manner. The first process that was classified as quorum sensing-dependent was bioluminescence [10]. In this process, it is particularly understandable that the energy-dependent process of light emission is initiated only when the density of organisms would allow the production of detectable light signals. Later, other processes were also revealed to be quorum sensing-dependent, including for instance, the production of pathogenicity factors or biofilm formation. Among Gram-negative organisms, four characteristics seem to be present in most quorum-sensing systems. First, acylhomoserine lactones or molecules synthesized from $\mathrm{S}$-adenosylmethionine are mostly used as quorum-sensing molecules. Second, the quorum-sensing molecules can diffuse through the bacterial membranes. Third, quorum-sensing changes the expression of a multitude of genes, and last but not least, quorum sensing leads to autoinduction of genes necessary for messenger molecule production [11]. Nevertheless, exemptions from these rules have been presented many times. For instance, in Shewanella baltica, quorum sensing was discovered to be dependent on diketopiperazines, a class of small cyclic peptides [12]. These compounds were previously identified as belonging to a family of molecules used for interspecies or interkingdom communication [13]. Nevertheless, S. baltica relies on these substances for quorum sensing-induced pathogenesis while production of acyl-homoserines has not been detected so far.

In this study, we reveal that low riboflavin concentrations induce a specific transcriptomic response in a concentration-dependent manner in S. oneidensis. The addition of riboflavin triggers overexpression of one single gene, which encodes the ornithine-decarboxylase speC. The activity of the corresponding enzyme most probably leads to a proteomic response potentially based on putrescine-dependent regulation. Part of this response involves overproduction of proteins involved in biofilm production. Using data on riboflavin formation by planktonic and biofilm cells, we established a model that helped predict the necessary cell concentration and time to reach sufficient riboflavin concentration to start the respective physiological response of the organisms. The results reveal a novel target to increase current density in bioelectrochemical systems.

\section{Results \\ Riboflavin addition triggers a specific transcriptomic response}

Riboflavin addition causes enhanced biofilm and current production in BESs $[14,15]$. This process could occur for two different reasons: (I) addition of an electron shuttle sustains growths of more cells that cannot be in direct contact with the anode or (II) external riboflavin triggers biofilm formation. In this case the higher cell density on the anode would, as a secondary effect, lead to higher current densities. In order to investigate this second hypothesis, a transcriptomic analysis was conducted using cells that were either grown with or without the addition of $37 \mathrm{nM}$ riboflavin, a concentration that was also used in a previous study [14]. To exclude the effects of riboflavin on gene expression due to its electron shuttling function and focus on its potential role as messenger molecule, fumarate, instead of an anode, served as electron acceptor.

Comparison of the two transcriptomes revealed that only one gene, speC, encoding for the ornithine decarboxylase of the organism was significantly upregulated with more than a twofold change (FDR $p$-value $\leq 0.05$, Table 1). SpeC facilitates the production of the polyamine putrescine.

To prove whether an increase in expression of this gene causes higher currents and accelerated biofilm production after riboflavin addition in BES, the gene was expressed from an inducible plasmid in S. oneidensis wild type. As depicted in Fig. 1, the positive effect of speC-overexpression on current production and biofilm 
Table 1 Significantly regulated genes after riboflavin addition

\begin{tabular}{lc}
\hline Gene & $\begin{array}{l}\text { Fold change (FDR } \\
\boldsymbol{p} \text {-value) } \\
\text { Riboflavin addition vs. } \\
\text { no riboflavin addition }\end{array}$ \\
\hline speC & $2.04(1.92 \mathrm{E}-10)$ \\
srtA & $-2.04(4.24 \mathrm{E}-3)$ \\
prpR & $-2.05(6.61 \mathrm{E}-4)$ \\
prpB & $-2.2(2.86 \mathrm{E}-5)$ \\
\hline
\end{tabular}

Genes with a FDR $p$-value lower than 0.05 and a fold change higher than 2 or lower than -2 are shown. For all genes scored, the fold change was calculated by dividing the mutant value by the wild type value. If the number was less than one the negative reciprocal is listed

formation was almost identical to the effect of adding $37 \mathrm{nM}$ riboflavin. Moreover, speC deletion mutants were not capable of responding to the addition of this riboflavin concentration (Fig. 1). However, complementation of the speC deletion using a multicopy plasmid led to a similar current density and biofilm formation as riboflavin addition or speC overexpression. Furthermore, addition of $37 \mathrm{nM}$ riboflavin to a strain that overexpresses speC did not lead to a further increase in cell number or current. Hence, at this concentration, potential electron shuttling by riboflavin cannot further accelerate electron transfer in cells that overexpress speC. Producing a similar effect of enhanced current production via the addition of putrescine to the medium was also attempted. Still, the addition of putrescine at a concentration range between 0.5 and $5 \mu \mathrm{M}$ did not lead to a significant increase in current densities (Additional file 1: Fig. S1).

Besides speC, only three other genes were significantly regulated with a more than twofold change. The $\operatorname{srt} A$ gene was downregulated twofold. This gene encodes a putative sortase, a class of enzyme that catalyzes the covalent attachment of specific proteins to the cell wall of Gram-positive and occasionally Gram-negative bacteria [16]. Furthermore, the genes for $p r p R$ and $p r p B$ (2.1and 2.2-fold, respectively), which are both involved in propionate degradation, were downregulated. Although

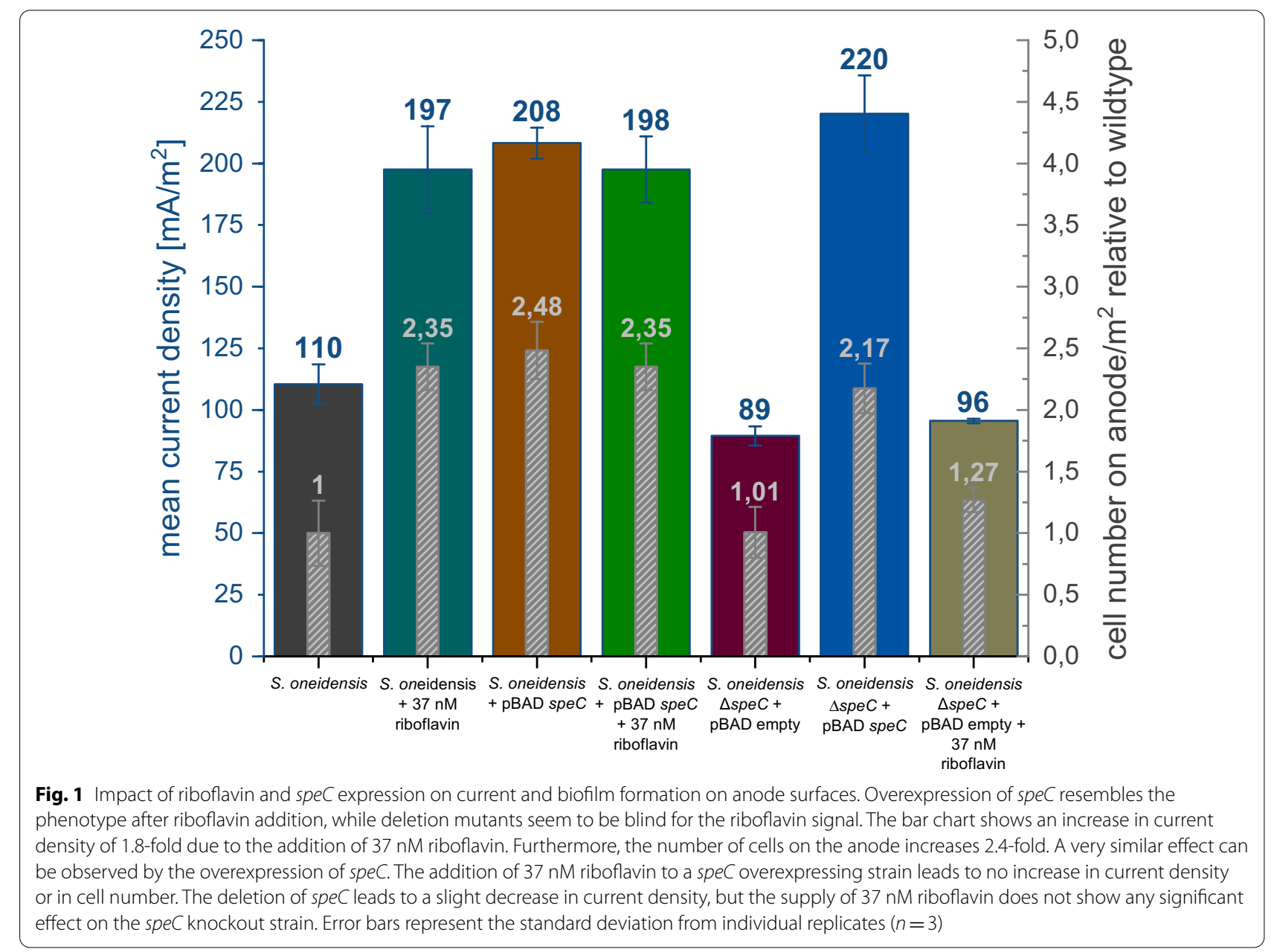




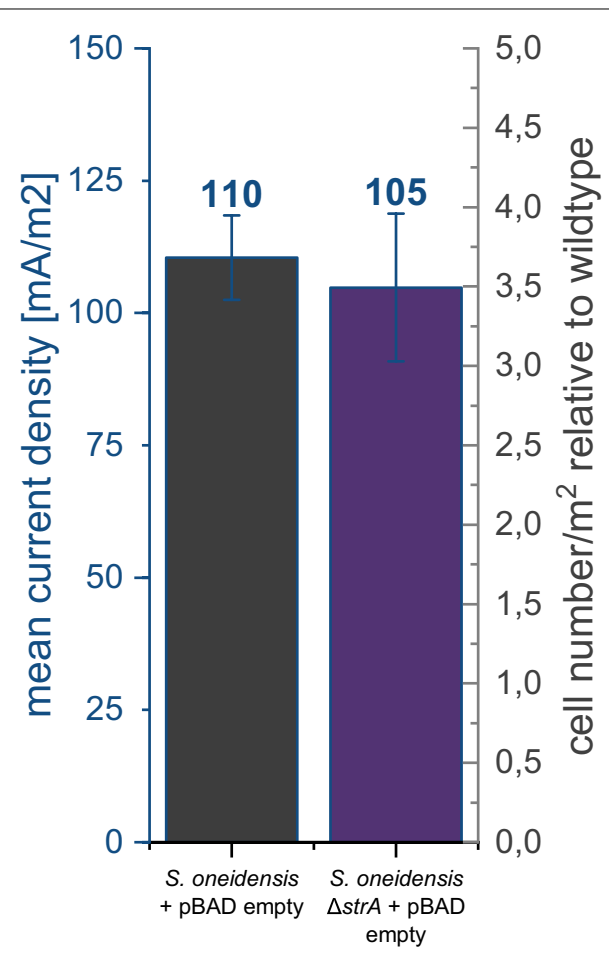

Fig. 2 Impact of srtA deletion on current generation and biofilm formation on anode surfaces. The bar chart shows that the knockout of srtA does not have any significant effect on the current density. Error bars represent the standard deviation from individual replicates $(n=3)$

the previous experiments revealed that speC overexpression was sufficient to completely mimic the effect of riboflavin addition, we also analyzed the potential effects of the sortase as its activity might have an effect on the surface chemistry of the organisms. Still, deletion of $s r t A$ gene from the genome of the organism did not lead to an increase in current density as would have been expected if the sortase was involved in the observed increased biofilm production (Fig. 2). Of note, it has not yet been possible to generate deletion mutants in $p r p R$ and $p r p B$.

\section{Identifying the minimal riboflavin threshold for speC induction}

Riboflavin is excreted by the cells during growth and its concentration consequently increases over time in a batch system (Fig. 3). Riboflavin concentrations in batch experiments have been reported so far depending on growth conditions between 30 and $450 \mathrm{nM}$ [17-19]. Since we hypothesized that riboflavin could be a quorum-sensing molecule that is used by the cells to initiate a cell concentration-dependent physiological response, we quantified the response of the speC promoter on the addition of riboflavin at concentrations between 0 and $100 \mathrm{nM}$. The expression of the speC gene was measured via quantitative polymerase chain reaction (qPCR) as shown in Fig. 4. While the addition of 5-15 nM riboflavin showed a slight decrease in speC-expression, we observed a distinct upregulation after addition of more than 15 nM. A similar increase in speC expression was observed in a growth experiment without external addition of riboflavin. Expression increased as soon as the cellular riboflavin excretion led to medium concentrations of $15 \mathrm{nM}$ (Additional file 1: Fig. S2). Moreover, the response was specific to this flavin species as the addition of flavin-adenine-dinucleotide (FAD) or

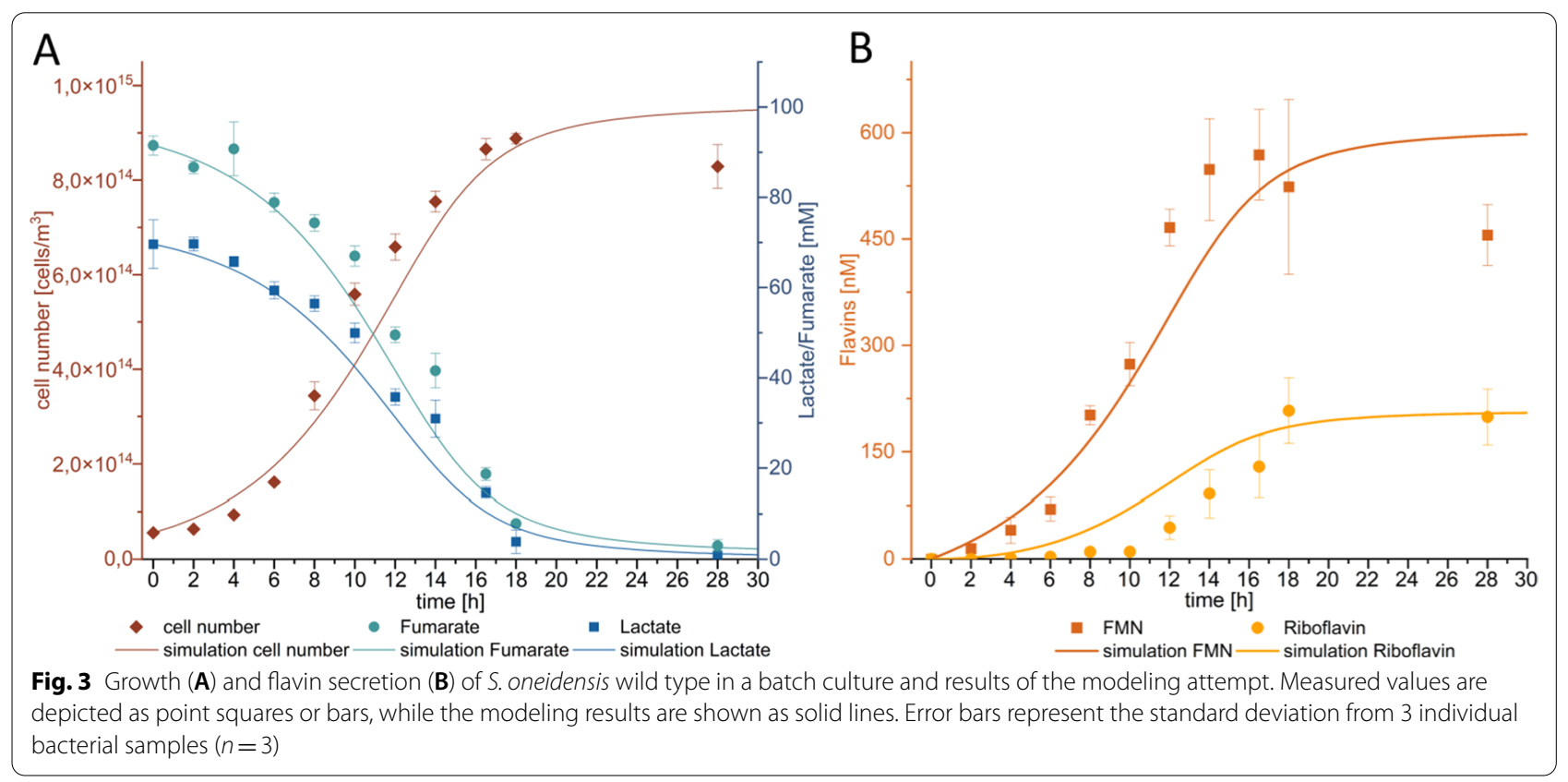



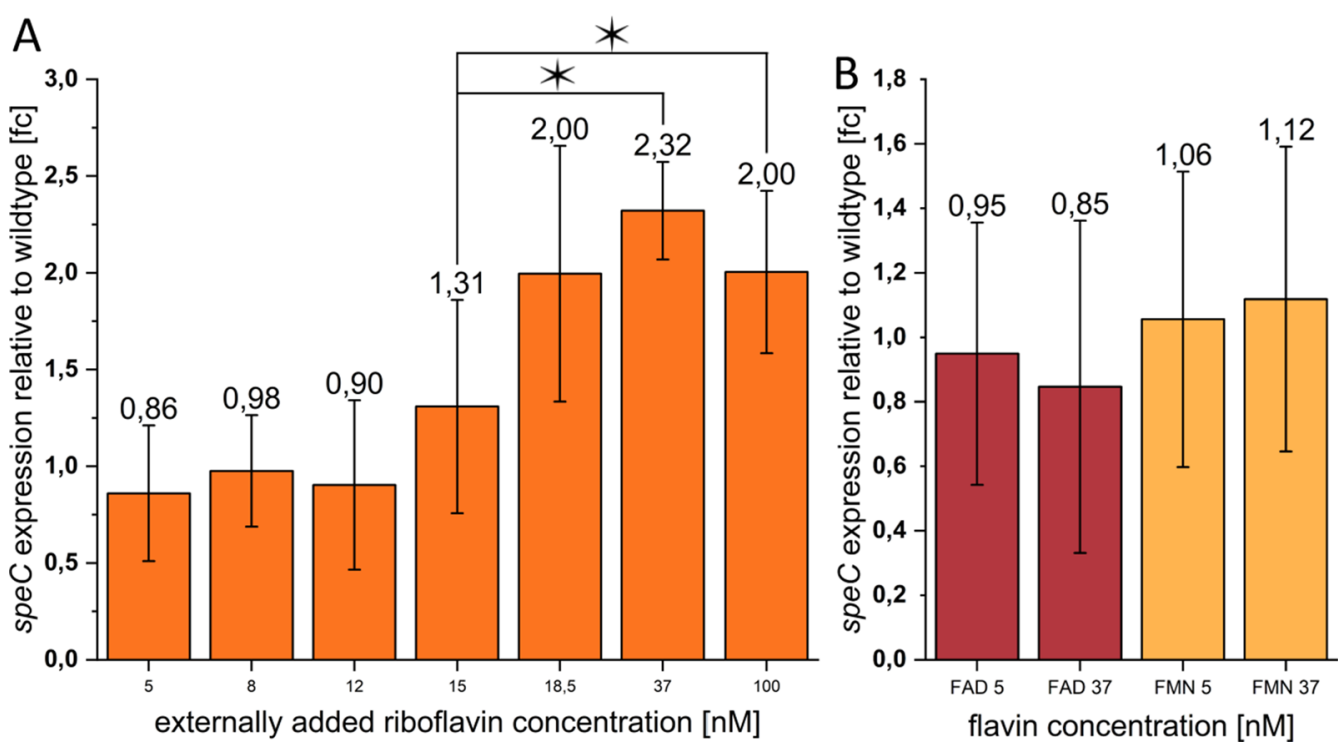

Fig. 4 A speC expression after the addition of different concentrations of riboflavin relative to transcript abundance without riboflavin addition. The addition of up to $15 \mathrm{nM}$ riboflavin does not have any significant effect on speC expression, while the addition of 18.5, 37 and $100 \mathrm{nM}$ riboflavin leads to a 2- and 2.3-fold increase in speC expression, respectively. Error bars represent the standard deviation from individual replicates $(n=3)$. B speC expression after the addition of different concentrations of flavin adenine dinucleotide (FAD) and flavin mononucleotide (FMN) relative to cells without exogenous flavin addition. The addition of FAD and FMN in these concentrations does not have a significant effect on speC expression. Expression is normalized to the gene for the RNA polymerase subunit rpoA. Error bars represent the standard deviation from individual replicates $(n=3)$. Asterisks represent significant differences (unpaired $t$-test $p<0.05)$

flavin-mononucleotide (FMN) could not trigger a similar response (Fig. 4).

\section{Post-transcriptional effect of SpeC}

So far, the experiments revealed that riboflavin triggers a concentration-dependent specific response of the speC-promoter, which in turn leads to biofilm production and enhanced current densities. Still, since no other gene was significantly upregulated in our study and since the genes that were downregulated also do not have a function regarding the observed biofilm phenotype, we asked whether the overexpression of speC might have an effect on the cell proteome. To this end, a quantitative proteomic study to compare the proteome of cells with and without speC overexpression was conducted. Again, the set of significantly differentially expressed proteins was limited (Table 2). Among them, we found that PuuA, which is involved in putrescine degradation, was more highly produced when $s p e C$ was overexpressed. Conversely, less AguB, which is involved in putrescine production, was produced. Although many of the differentially produced proteins cannot be linked to the observed biofilm phenotype, we found at least six proteins that were previously reported to have a putative function that could explain increased biofilm formation. Two of the overproduced proteins, WbpP and ProQ, were previously shown to be important for biofilm or capsule formation [20-22]. WbpP is a putative UDP$\mathrm{N}$-acetylglucosamine $\mathrm{C} 4$ epimerase. The corresponding gene seems to form an operon with $w b p A$, which encodes a UDP-D-GlcNAc dehydrogenase. WbpA was revealed to be slightly overproduced although with standard deviations that excluded statistical significance. Furthermore, ProQ, a posttranscriptional regulator in E. coli that positively affects biofilm formation [23], is overproduced. Among the proteins that were downregulated when speC was overexpressed, is SO_1208, a protein containing a GGDEF and an EAL-domain. Proteins containing these domains are often involved in adjusting intracellular levels of cyclic-di-GMP, a key messenger molecule for regulating biofilm formation. Furthermore, two putative proteases and a short chain dehydrogenase (SO_2766, SO_0491 and SO_1674) are under-expressed. Related proteins in other organisms were previously shown to be involved in cell detachment [24-26].

\section{Modeling riboflavin production in a batch culture}

Our next aim was to assess the necessary cell concentrations and times to reach the riboflavin threshold concentration for biofilm production (Fig. 4). Hence, the kinetic and stoichiometric values for riboflavin production were determined from a culture growing anoxically with lactate and fumarate (Fig. 4). The data depicted in Fig. 4 corroborate data from other research groups 
Table 2 Significantly regulated proteins due to speC expression

\begin{tabular}{|c|c|}
\hline Protein & $\begin{array}{l}\log _{2} \text { fold } \\
\text { change } \\
\text { (p-value) } \\
\text { speC } \\
\text { expression vs } \\
\text { wild type }\end{array}$ \\
\hline SpeC & $9.65(5 \mathrm{E}-06)$ \\
\hline SO_3964 & 4.09 (0.0445) \\
\hline $\operatorname{ArgB}$ & $3.22(2 \mathrm{E}-06)$ \\
\hline SO_0576 & $2.5(2 \mathrm{E}-05)$ \\
\hline DctP & $2.32(0.0026)$ \\
\hline IVdG & $2.32(0.0208)$ \\
\hline ProQ & $2.08(0.0308)$ \\
\hline SO_3698 & $1.75(0.0426)$ \\
\hline ThiL & $1.7(8 \mathrm{E}-06)$ \\
\hline SO_4371 & $1.67(0.0215)$ \\
\hline GarR & $1.64(0.0005)$ \\
\hline PuuA & $1.53(0.0002)$ \\
\hline AdhB & $1.53(0.0003)$ \\
\hline LeuB & $1.49(0.0117)$ \\
\hline Tpx & $1.46(0.0175)$ \\
\hline HemL & $1.4(0.0003)$ \\
\hline YebR & $1.31(0.0445)$ \\
\hline MetH & $1.26(0.0349)$ \\
\hline WbpP & $1.23(0.0004)$ \\
\hline SelD & $1.14(0.0009)$ \\
\hline RmlA & 1.09 (0.0017) \\
\hline Upp & $1.06(0.0045)$ \\
\hline TrpA & $1.03(9 \mathrm{E}-05)$ \\
\hline SO_2766 & $-1.09(0.0047)$ \\
\hline SO_1059 & $-1.27(0.0114)$ \\
\hline AguB & $-1.29(0.0008)$ \\
\hline SO_4378 & $-1.33(0.0004)$ \\
\hline SO_A0051 & $-1.35(0.0004)$ \\
\hline SO_0695 & $-1.43(0.0262)$ \\
\hline Rnr & $-1.46(0.0007)$ \\
\hline SO_4429 & -1.57 (0.0309) \\
\hline SO_0491 & $-1.66(0.0195)$ \\
\hline SO_3119 & $-1.97(6 \mathrm{E}-05)$ \\
\hline SO_2636 & $-2.01(0.0027)$ \\
\hline SO_1208 & $-2.02(0.0021)$ \\
\hline SO_1674 & $-2.25(0.0218)$ \\
\hline RpoE & $-2.69(0.0391)$ \\
\hline
\end{tabular}

Proteins with a $p$-value lower than 0.05 and a $\log _{2}$ fold change greater than 1 or lower than -1 are shown

demonstrating that FMN is released by the cells and gets slowly converted into riboflavin. The latter reaction is supposed to proceed abiotically. Nevertheless, a comparison of the FMN and riboflavin concentrations after 18 and $28 \mathrm{~h}$ suggests that active growth is required for this

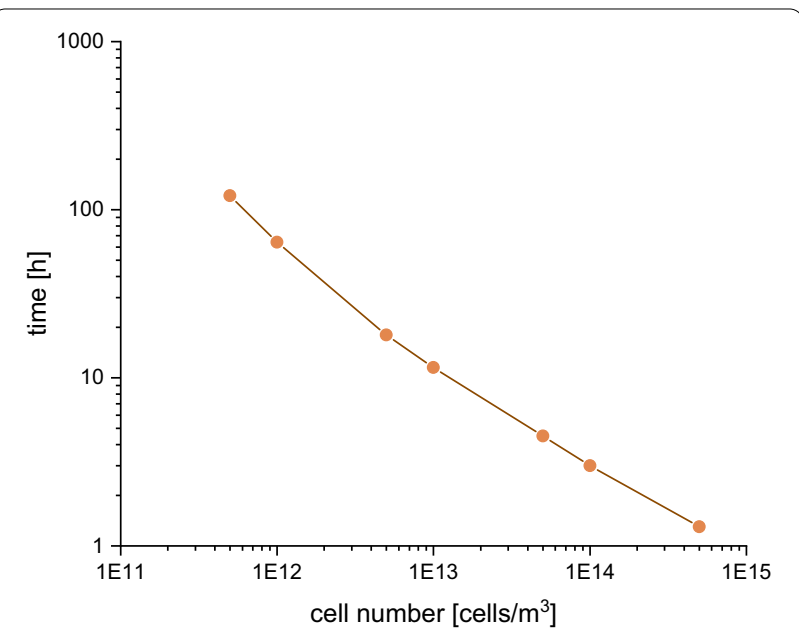

Fig. 5 Exemplary prediction of time needed to produce $18 \mathrm{nM}$ riboflavin with different cell numbers. The delineation is based on the model described in the text and supplemental material

reaction as the riboflavin concentration does not significantly increase within this time frame although sufficient amounts of FMN are still available.

Using the data from Fig. 4, we formulated a model for the production process that was applied to determine a time/cell number dependency for the accumulation of $18.5 \mathrm{nM}$ riboflavin (see Additional file 1: Table S3). The model (supplementary material) describes cell growth based on Monod terms with an electron acceptor (fumarate) and electron donor (lactate). FMN production is described as a growth-related process, whereas the formation of riboflavin from FMN occurs according to first-order kinetics. We had to combine the first-order formation with the two above mentioned Monod terms as the experimental results indicate riboflavin production stops as soon as the substrate is depleted.

Using this model, it was possible to predict the time required for a culture of a certain density to produce the necessary $18.5 \mathrm{nM}$ riboflavin to trigger the biofilm formation response (Fig. 5). The estimated time intervals seem reasonable if the cells could grow in an environmental setting that is characterized by a limited continuous inflow of water and similar to a laboratory batch system.

\section{Realization of riboflavin-based messaging is possible in a biofilm setup}

Planktonic growth in open water and not in a laboratory batch system will always cause dilution of the excreted riboflavin to values below the cellular detection limit. Consequently, the dependencies described above will be applicable in nature only under conditions in which an enclosed environment develops, for instance, in a lagoon 
setting. Still, the natural way of living of most microorganisms is in the form of a biofilm. Hence, we asked whether retention of riboflavin in a S. oneidensis biofilm or more specifically in its extracellular polymeric substances (EPS) could be sufficient to reach necessary riboflavin concentrations.

The $S$. oneidensis biofilm was grown in a microfluidic device under constant flow. Finally, a mean biofilm thickness of $76.3 \pm 12.9 \mu \mathrm{m}$ was reached (Fig. 6). After $121 \mathrm{~h}$, no measurable lactate in the effluent was found. In contrary to the batch experiment, after $97 \mathrm{~h}$ riboflavin was the dominant flavin species in the effluent of the system. After $143 \mathrm{~h}$, the biofilm was lysed, and the flavin content was measured. Using optical coherence tomography (OCT)-data for biofilm volume, it was possible to determine the concentration of the different flavin species. The biofilm contained $3670 \pm 224 \mathrm{nM}$ riboflavin, $213 \pm 19 \mathrm{nM}$ FMN, and $292 \pm 47$ nM FAD. Hence, the observed flavin concentration was far above the identified concentration for riboflavin-based biofilm production. We sought to determine only the extracellular riboflavin concentration by carefully resuspending the developed biofilm. Nevertheless, we also measured the intracellular riboflavin concentration to exclude the possibility that partially lysed cells could have greatly contributed to the riboflavin concentration. The riboflavin content within the cells was at a level of $2.81 \times 10^{-3} \mathrm{fM}$ per cell. Thus, $5.15 \times 10^{10}$ cells/ $\mathrm{ml}$ (as in the analyzed biofilm) would contain $144.72 \mathrm{nM}$ of intracellular riboflavin, which is more than one magnitude below the measured value of $3670 \mathrm{nM}$. This finding agrees with the observation of von Canstein and colleagues, who could only measure trace amounts of riboflavin in the cytoplasm [27].

We also aimed to model riboflavin production in the biofilm system based on the quantitative data depicted in Fig. 6. Model description and simulation results are provided in the supplementary material. For our purpose, the biofilm model was mainly used as analytical tool. In fact, the simulation results (Additional file 1: Fig. S4) show one clear result. The release of product (riboflavin) from biofilm into the bulk medium cannot solely be explained by a traditional reaction diffusion approach for biofilm systems [28]. Obviously, part of riboflavin product is not directly released into the bulk liquid. To fit the simulation with the achieved results, it was necessary to reduce the diffusion coefficient of riboflavin in water by three orders of magnitude. Moreover, yield coefficients for biomass and product and the first-order

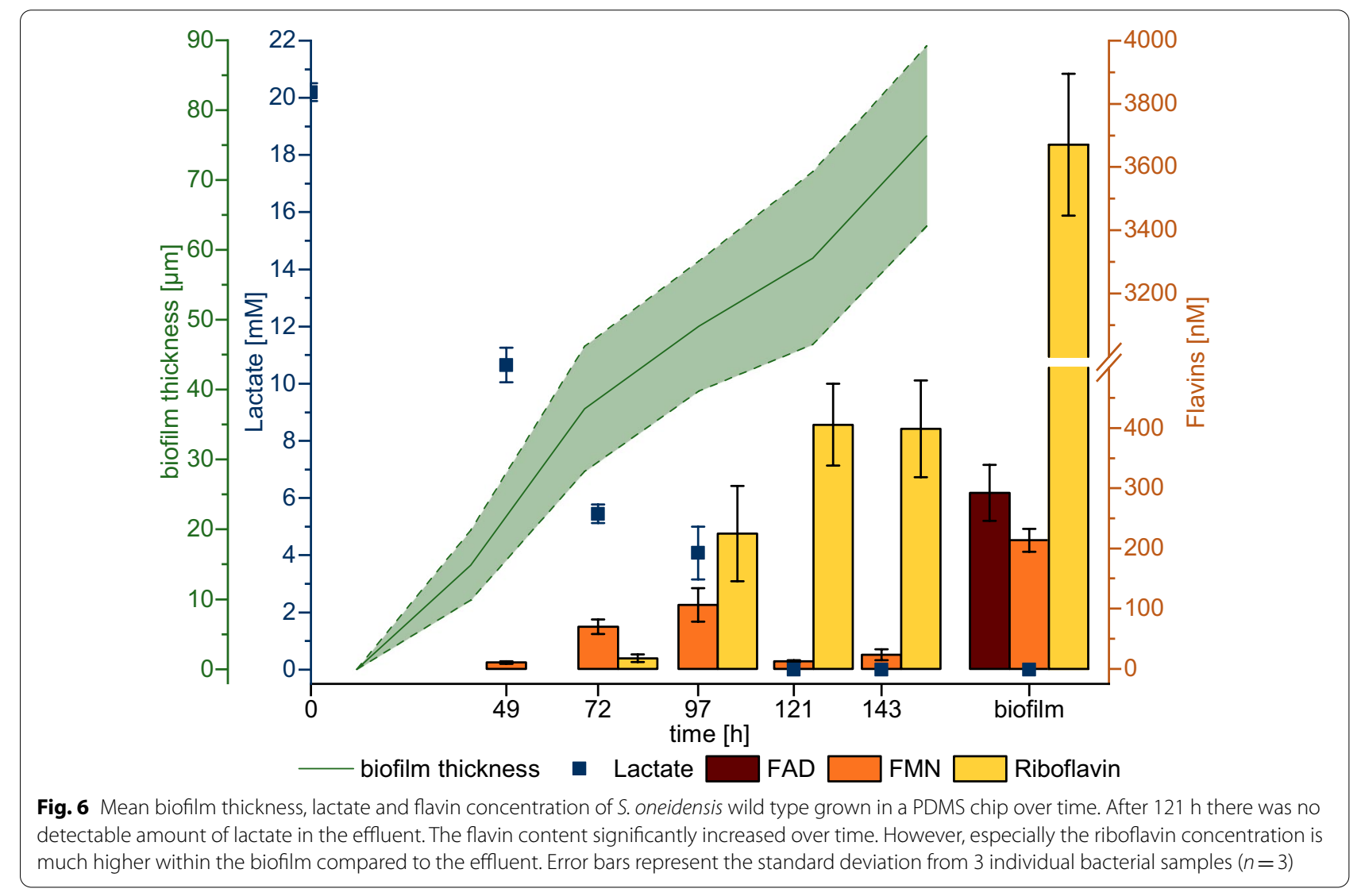


reaction constant for FMN transformation to riboflavin had to be adapted and compared to the values measured in the batch culture (see Additional file 1: Table S3). We assumed that the two orders of magnitude higher cell density within the biofilm had an impact on yield coefficient for FMN and first-order reaction rate for riboflavin from FMN.

Biofilm thickness and lactate consumption in the flow cell can be displayed very satisfactorily with the chosen model. However, for both FMN and riboflavin, the simulation shows release from the biofilm into the bulk liquid starting already on the first day. The experimental results clearly show that the cells do not release the products that fast. The decreased diffusion coefficient for riboflavin allows for an adequate simulation of its concentration within the biofilm after $140 \mathrm{~h}$ (Additional file 1: Fig. S4e). However, the concentrations of riboflavin in bulk and biofilms can be misleading. In fact, the total amount of riboflavin within the biofilm after $140 \mathrm{~h}$ is only $4.6 \times 10^{-3} \mathrm{nmol}$, and the riboflavin produced by the biofilm (and transported out of the system) totals $24 \mathrm{nmol}$.

\section{Discussion}

This study revealed that $S$. oneidensis cells can sense the extracellular riboflavin concentration and use this information to initiate an intracellular process leading to biofilm formation. The increased biofilm formation leads to significantly increased current densities in bioelectrochemical systems. This process is apparently based on an overproduction of proteins triggered by the intracellular activity of SpeC. Among the overproduced proteins is WbpP, a key protein for extracellular matrix production $[20,21]$. Modeling and biofilm experiments showed that the necessary riboflavin concentration in biofilms can be reached with a low number of attached cells. Moreover, comparing the model with experimental data from the biofilm analysis clearly indicates a specific retention of riboflavin within the biofilm matrix.

The observed riboflavin-dependent response of the cells is not in line with canonical quorum-sensing systems. It does not operate with an acylhomoserine lactone, and autoinduction of the signaling cascade could not be observed. Moreover, the final response does not directly depend on the transcription level. Nevertheless, riboflavin is produced in a growth-dependent manner and leads at a distinct threshold to a specific recognition by the cells. Moreover, the physiological biofilm formation response is similar to other quorum sensing-based systems. Hence, we hypothesize that riboflavin should be added to the list of quorum-sensing molecules. As mentioned above, other non-canonical quorumsensing mechanisms have already been described in other Shewanella species. Thus, the use of alternative quorum-sensing mechanisms might be a general characteristic of the genus. Still, a link between riboflavin as potential quorum-sensing molecule and the canonical $\mathrm{N}$-acyl homoserine lactone messengers was provided in a study by Rajamani et al. [29]. The authors observed that cultures of the alga Chlamydomonas produced and secreted lumichrome into the culture supernatant. Lumichrome is a derivative of riboflavin. Moreover, the authors detected that lumichrome and riboflavin could stimulate the quorum-sensing receptor LasR from Pseudomonas aeruginosa. Hence, riboflavin could be a ubiquitous communication molecule that operates among different kingdoms [29].

Ding and colleagues observed the impact of polyamines on aerobic biofilm production by $S$. oneidensis [30]. Using a transposon screen, the authors discovered a mutant that apparently produced more EPS compared to the wild type. Detailed analysis revealed a twofold increase in EPS production and that the gene encoding the ornithine decarboxylase speF (an isoenzyme of SpeC) was interrupted by transposon integration. The mutant was hyper-adherent and formed tower-like biofilms when examined in static biofilm assays. Still, Ding and colleagues conducted experiments under oxic conditions, and the requirements for an efficient anaerobic biofilm system thriving with an insoluble electron acceptor seem to be quite different. For instance, EPS production per se can have also an insulating effect as shown in a variety of studies [31-33]. Moreover, efficient electron transfer demands confluent coverage of the biofilm substrate and not tower-like biofilm structures as observed by Ding et al. [30]. The latter will simply not lead to an optimized distance between the bulk of the cells and the electron acceptor. Nevertheless, we tested also the influence of speF on current production in a BES. As expected, a marker-less speF mutant produced less current compared to the wild type (Additional file 1: Fig. S3).

The observed cellular response was riboflavin-specific as other flavin molecules did not lead to speC-overexpression. Flavin excretion starts with the export of FAD from the cytoplasm by the specific transporter Bfe. In the periplasm, FAD is used as cofactor and to a certain extent hydrolyzed to FMN and AMP by the periplasmic 5 ' nucleotidase UshA [34]. In line with the UshA activity in the periplasm, FMN is the main flavin species under planktonic conditions followed by significantly lower levels of riboflavin [3, 27, 34]. Hence, the cells do not detect the flavin molecule with the highest concentration, but the molecule that is formed by slow hydrolysis of FMN. This process causes a time-delayed cellular response to flavins in the environment, which might have evolved to avoid a cellular response that is too rapid. In fact, evolution might have selected a response that is dependent on 
a diffusion-limited or batch environment in which the conditions are stable enough to allow enough time for FMN-hydrolysis to proceed and sufficient concentrations of riboflavin to accumulate. In a biofilm setting, the cells apparently evolved further measures to increase the local riboflavin concentration by retention of this substance. Therefore, already low cell numbers will trigger the SpeCdependent biofilm formation response.

The results favor a post-transcriptional impact of putrescine on protein production. Of note, this kind of regulatory function of putrescine has so far only been observed for the gene cluster involved in putrescine degradation in E. coli, while a rather global impact on gene regulation was observed only in eukaryotic organisms [35-37]. To date, it can only be assumed that putrescine binding to proteins or RNA will affect translation or the stability of proteins and mRNA involved in the observed response. Of great importance for the biofilm formation response might be WbpP, which was shown to be necessary for capsule formation in different strains [20, 21]. The biochemical pathway for capsule formation has been widely studied in Pseudomonas strains. Here, glucose1 -phosphate is converted to UDP- $N$-acetyl-D-glucosamine, which is the central precursor of surface-associated carbohydrate synthesis. UDP- $N$-acetyl-D-galactosamine is then formed by the $\mathrm{WbpP}$-catalyzed $\mathrm{C}_{4}$ epimerization of UDP- $N$-acetyl-D-glucosamine $[38,39]$. Dehydrogenation of the latter leads to the production of UDP- $N$-acetylD-galactosaminuronic acid. WbpP together with WbpA seems to form an operon in S. oneidensis. The latter converts UDP- $N$-acetyl-D-glucosamine to the corresponding uronic acids [22, 40]. Hence, both enzymes compete for the same substrate. The observed post-transcriptional regulation leading to a higher production of $\mathrm{WbpP}$ compared to WbpA might be a way to fine-tune the chemical composition of the capsule polysaccharide. Within the set of over- and underproduced enzymes, PuuA and AguB, respectively, were also detected. Hence, the cell also initiates countermeasures for putrescine production using SpeC-based regulation, which would likely be necessary for cellular homeostasis of this polyamine. It was observed that the external addition of putrescine did not lead to a stimulating effect on anaerobic biofilm formation. So far, we can only speculate that it is not possible to adjust the intracellular putrescine concentration by the external addition in a similar way compared to the endogenous production. Although $S$. oneidensis has the genetic information for putrescine import (SO_1270, SO1271, SO_1272, SO_1273_SO_0313), it is questionable whether the cells will induce the corresponding genes under conditions in which nitrogen and carbon are not limiting. Moreover, the external addition of putrescine per se will have an effect on biofilm formation since polyamines as cations will bind to negatively charged surface groups as for instance the lipopolysaccharide. This effect could potentially mask the here observed positive effect on biofilm formation.

We developed a model for riboflavin production with the aim of specifying the number of organisms and the volume in which the organisms have to thrive to accumulate the necessary amount of riboflavin. The quantification of flavins in the biofilm-matrix indicate a rather high concentration that could not be correlated with the results from the planktonic experiments and the model based on the riboflavin diffusion coefficient, the average biofilm volume, and the average cell number per biofilm volume. The most probable explanation for this experimental result is that riboflavin is bound by the cells and/or the biofilm matrix. As cofactors, flavins are attached to the outer membrane cytochromes on the cell surface. Previous research revealed that the number of outer membrane cytochromes on the cell surface is between 1000 and 30,000 proteins per $\mu \mathrm{m}^{2}$ [41, 42]. Using the average dimension of Shewanella cells (6.79 $\mu \mathrm{m}^{2}$ ) revealed by Sturm et al. [43] and the average number of cells per mL biofilm $\left(5.15 \times 10^{10}\right)$, we can assume that the biofilm will contain between $3.49 \times 10^{14}$ and $1.05 \times 10^{16}$ outer membrane cytochromes per $\mathrm{mL}$. This number is within the range of the measured riboflavin concentration of $3670 \pm 224 \mathrm{nM}$ riboflavin; which would be equivalent to $2.21 \times 10^{15}$ riboflavin molecules per $\mathrm{mL}$. Hence, outer membrane cytochrome-based retention of riboflavin likely allows for riboflavin-based messaging even under environmental conditions, such as those characterized by constant mixing. In other words, the observed process probably allows quorum sensing under conditions that would not lead to a cellular response with a canonical quorum-sensing molecule that is quickly washed out of the biofilm by the medium flow.

\section{Conclusion}

This study revealed that $S$. oneidensis can sense the extracellular concentration of riboflavin and responds with enhanced biofilm formation to increasing riboflavin concentrations. This biofilm formation response leads to increased current densities in bioelectrochemical systems. Interestingly, increased biofilm formation does not necessarily lead to higher current densities as some biofilm morphologies or compositions can have an insulating effect. On the contrary, overexpression of speC leads to significantly increased biofilm formation and current densities using the riboflavin signaling pathway. We suggest that this gene will be an important factor for future strain development in the field of bioelectrochemical systems. 


\section{Materials and methods}

\section{Media and growth conditions}

All strains used in this study are listed in Additional file 1: Table S1. S. oneidensis was precultured under oxic con-

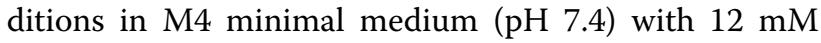
HEPES buffer and $70 \mathrm{mM}$ lactate as electron donor. The medium was prepared as previously described [14]. After $8 \mathrm{~h}$ of oxic growth, $S$. oneidensis was transferred to anoxic M4 medium containing $70 \mathrm{mM}$ lactate as electron donor and $100 \mathrm{mM}$ fumarate as electron acceptor. Oxygen was removed from the media via the repeated application of a vacuum and following sparging of the headspace with $\mathrm{N}_{2}$. The initial $\mathrm{OD}_{600}$ of the anoxic culture was set to 0.05 . For genetic modifications, the strains were grown in LB medium under oxic conditions at $37{ }^{\circ} \mathrm{C}$ (E. coli) or $30^{\circ} \mathrm{C}$ (S. oneidensis). If necessary, 2,6-diaminopimelic acid (DAP; $0.3 \mathrm{mM})$, kanamycin $(\mathrm{Km} ; 50 \mu \mathrm{g} / \mathrm{mL})$, and arabinose $(0.1 \mathrm{mM})$ were added to the medium.

\section{Construction of expression plasmids}

Plasmid pBAD202 was used for overexpression of the gene speC. The plasmid was cleaved using NcoI and PmeI. The speC gene was amplified from the S. oneidensis wild type genome. By using elongated primers (Primers 1 and 2, Additional file 1: Table S2), an overlap to the plasmid was added that was used for isothermal ligation as described by Gibson and colleagues [44]. The respective plasmid was verified by PCR analysis (Primers 3 and 4; Additional file 1: Table S2) and subsequent sequencing.

\section{Construction of marker-less deletion mutants}

Marker-less deletion of genes was conducted according to Schuetz et al. [45]. The respective pMQ150-based suicide vectors were also gained using isothermal in vitro recombination [44]. The pMQ150 vector was cleaved using BamHI and SalI. Fragments with lengths of $500 \mathrm{bp}$ up- and down-stream of the respective genes were amplified using primers 5-8 for speC deletion, primers 9-12 for $s r t A$ deletion, primers 13-16 for prpR deletion and primers 17-20 for $\operatorname{prpB}$ deletion (Additional file 1: Table S2). The fragments contained an overlap to the pMQ150 plasmid in addition to each other. The three fragments were used for isothermal ligation as described by Gibson and colleagues [44] and transformed into the E. coli mating strain WM3064 (kind gift of W. Metcalf, University of Illinois). The suicide vector was then conjugated into $S$. oneidensis. All further steps were conducted as described by Saltikov and Newman [46]. The respective deletions were verified by PCR analysis (Primers 21 to 26; Additional file 1: Table S2) and subsequent sequencing. For the marker-less deletion of prpR and
prpB only the integration of the pMQ150-based vectors in the $S$. oneidensis genome was successful. The deletion of the residual genes could not be accomplished.

\section{Bioelectrochemical system (BES)}

All BES experiments were conducted in triplicate using a single chamber BES with a working volume of $270 \mathrm{ml}$ [33]. Graphite felt (projected area of $36 \mathrm{~cm}^{2}$, SGL Group, Germany) and platinum mesh (projected area of 1.25 $\mathrm{cm}^{2}$, chemPUR, Germany) were used as working and counter electrode materials, respectively, and an $\mathrm{Ag} /$ $\mathrm{AgCl}$ electrode (Sensortechnik Meinsberg, Germany) served as the reference electrode. Prior to use, the working electrode was rinsed with isopropanol followed by deionized water. The complete BES setup was sterilized by autoclaving.

Before inoculating the reactors with microorganisms, cells were harvested from the anoxic preculture by centrifugation (7 min, $600 \mathrm{~g}$ ) and washed three times with medium not containing electron donor or electron acceptor. Afterwards, the cells were resuspended to a final $\mathrm{OD}_{600}$ of 0.07 in M4 medium containing $70 \mathrm{mM}$ lactate. For pBAD-plasmid containing strains $50 \mu \mathrm{g} / \mathrm{l}$ kanamycin and $0.1 \mathrm{mM}$ arabinose were added.

During chronoamperometric experiments, the working electrode was poised to $0 \mathrm{mV}$ versus a standard hydrogen electrode (SHE), and current was monitored for $46 \mathrm{~h}$. BES setups were constantly flushed with $\mathrm{N}_{2}$ gas in order to provide anoxic conditions. The medium was stirred constantly for thorough mixing.

\section{Flavin quantification}

For quantification of flavins, liquid samples from anoxic S. oneidensis wild type cultures were taken at different time points. The samples were filtered through a $0.2 \mu \mathrm{m}$-pore-size filter and analyzed by reversed-phase high-performance liquid chromatography ([HPLC]; Luna ${ }^{\circledR} 5 \mu \mathrm{m} \mathrm{C18(2)} 100 \AA$, $250 \times 4.6 \mathrm{~mm}$ column). The compounds were separated as previously described by van Canstein and colleagues [19] using a flow rate of $0.5 \mathrm{ml} / \mathrm{min}$. The concentration of flavins was determined using a fluorescence detector at 440 and $525 \mathrm{~nm}$ excitation and emission, respectively.

\section{DNA isolation for qPCR}

The innuPREP Stool DNA Kit (Analytic Jena, Germany) was used to isolate DNA according to the manufacturers' suggestions with minor modifications. Anodes from the BES setups were sliced into pieces, and $5 \mathrm{ml}$ of SLS buffer (Analytic Jena, Germany) was added. The samples were vortexed vigorously for $1 \mathrm{~min}$. Thereafter, the samples were incubated at $95{ }^{\circ} \mathrm{C}$ for $15 \mathrm{~min}$. The samples were 
vortexed every $5 \mathrm{~min}$. Afterwards, DNA isolation proceeded according to the manufacturer's protocol. Relative cell quantifications of anode samples were based on three individual BESs. Two slices of one anode were used as a technical duplicate. Hence, every quantitative PCR result is based on the quantification of six samples.

\section{qPCR}

For quantitative analysis of cell adhesion to the anode, a standard curve using biological triplicates of $S$. oneidensis wild type in six different dilutions was established. Before isolation of the DNA, the cells were counted in two different dilutions (Neubauer chamber improved, Friedrichsdorf, Germany). Quantitative PCR (qPCR) was conducted using primers 27 and 28 (Additional file 1: Table S2) according to Dolch et al. [47].

For quantification of speC transcripts, S. oneidensis wild type was grown in anoxic M4 minimal medium with the addition of $0,5,12,15,18.5,37$ and $100 \mathrm{nM}$ riboflavin. The cells were harvested after $5 \mathrm{~h}$ of growth. Furthermore, cells were grown in anoxic M4 media without the addition of riboflavin and samples were taken after 30, 60, 180, 300, 480 and $600 \mathrm{~min}$ of growth. From all samples the RNA was isolated using the RNeasy Mini Kit (Qiagen, Germany) according to the manufacturer's instructions. In order to remove any residual DNA, the samples were treated with RNase-free DNase (Qiagen, Germany) overnight. Afterwards, the RNA was transcribed into cDNA using the iScript ${ }^{\mathrm{TM}}$ Select cDNA Synthesis Kit with random primers (Biorad, Germany). The amount of speC transcripts was quantified using primers 29 and 30 (Additional file 1: Table S2) in a qPCR. To normalize the amount of speC transcripts, transcripts of the housekeeping gene $r p o A$ were quantified (primers 31 and 32, Additional file 1: Table S2).

\section{Transcriptomic analysis}

Transcriptomic analyses were conducted with cells that were inoculated in anoxic M4 minimal media with $70 \mathrm{mM}$ lactate as electron donor and $100 \mathrm{mM}$ fumarate as electron acceptor. The starting $\mathrm{OD}_{600}$ was 0.2 . After $5 \mathrm{~h}$ of growth, cells were harvested by centrifugation $(7 \mathrm{~min}$, $6000 \mathrm{~g}, 4{ }^{\circ} \mathrm{C}$ ). The supernatant was discarded, and pellets were frozen using liquid $\mathrm{N}_{2}$. For each analysis, two biological triplicates were combined into one sample, resulting in two transcriptomic samples per condition.

mRNA extraction and Illumina sequencing were conducted by IMGM Laboratories (Martinsried, Germany). Bioinformatic analysis was performed using the CLC Genomics Workbench version 12.0.3 (https://www.qiage nbioinformatics). Prior to mapping, low-quality reads were trimmed. The 75-nt single end sequencing reaction yielded 15 million reads on average (after trimming) mapping concordantly to the $S$. oneidensis MR-1 reference genome. The coverage was 233 -fold. Transcript per kilobase million (TPM) values were used for comparison, and false discovery rates (FDR) $p$-values $\leq 0.05$ account for statistical significance.

\section{Mass spectrometry-based quantitative proteomic analysis} Proteomic analyses were conducted with cells that were inoculated in anoxic M4 minimal media with $70 \mathrm{mM}$ lactate as electron donor and $100 \mathrm{mM}$ fumarate as electron acceptor. The starting $\mathrm{OD}_{600}$ was 0.2 . After $5 \mathrm{~h}$ of growth, cells were harvested by centrifugation $(7 \mathrm{~min}, 6000 \mathrm{~g}$, $4{ }^{\circ} \mathrm{C}$ ). The supernatant was discarded, and pellets were resuspended in TRIS buffer ( $\mathrm{pH}$ 6.8). Cells were lysed by two passages through a French Press.

The protein content of samples was quantified using the Bradford assay [48] with bovine serum albumin as standard. The protein concentration was then adjusted to $1 \mu \mathrm{g} / \mu \mathrm{l}$.

Cell lysates were mixed with Laemmli buffer [49] and then stacked in a single band in the top of a sodium dodecyl sulfate-polyacrylamide gel electrophoresis (SDS-PAGE) gel (4-12\% NuPAGE gel, Invitrogen, Illkirch-Grafenstaden/France). After staining with R-250 Coomassie Blue (Biorad, Schiltigheim/France), proteins were digested in-gel using modified trypsin (sequencing grade, Promega, Charbonnières les Bains/France) as previously described [50].

Resulting peptides were analyzed by online nanoliquid chromatography coupled to tandem mass spectrometry (MS) (Ultimate 3000 RSLCnano and Q-Exactive HF, Thermo Scientific, Illkirch-Grafenstaden/ France). For this purpose, peptides were sampled on a $300 \mu \mathrm{m} \times 5 \mathrm{~mm}$ PepMap C18 precolumn (Thermo Scientific, Illkirch-Grafenstaden/France) and separated on a $75 \mu \mathrm{m} \times 250 \mathrm{~mm} \mathrm{C18}$ column (Reprosil-Pur 120 C18-AQ, $1.9 \mu \mathrm{m}$, Dr. Maisch, Ammerbuch-Entringen) using a 180-min gradient. The MS and MS/MS data were collected by Xcalibur (version 4.1.31.9, Thermo Scientific, Illkirch-Grafenstaden/France). Peptides and proteins were identified by Mascot (version 2.6.0, Matrix Science, London/United Kingdom) through concomitant searches against the Uniprot database (S. oneidensis MR-1 taxonomy, January 2019 version), a homemade classical contaminant database, and the corresponding reversed databases. Trypsin/P was chosen as the enzyme, and two missed cleavages were allowed. Precursor and fragment mass error tolerances were set at respectively at 10 and $25 \mathrm{mmu}$. Peptide modifications allowed during the search were carbamidomethyl (C, fixed), Acetyl (Protein $\mathrm{N}$-term, variable) and oxidation ( $\mathrm{M}$, variable). The Proline software [51] was used to filter the results with conservation of rank 1 peptides, peptide score $\geq 25$, peptide 
length $\geq 7$ amino acids, FDR of peptide-spectrum-match identifications $<1 \%$ as calculated on peptide-spectrummatch scores by employing the reverse database strategy, and a minimum of 1 specific peptide per identified protein group. Proline was then used to perform a compilation, grouping and MS1 quantification of the validated protein groups.

The statistical evaluation was performed using the ProStar software (version 1.14) [52]. Proteins identified in the reverse and contaminant databases, and proteins quantified in less than three replicates of one condition were discarded from the list. After $\log 2$ transformation, abundance values were normalized by the vsn method before missing value imputation (slsa algorithm for partially observed values in the condition and DetQuantile algorithm for totally absent values in the condition). The statistical testing was conducted using limma. Differentially expressed proteins were sorted out using a log2 (fold change) cut-off of 1 and a $p$-value cut-off of 0.05 , allowing an FDR inferior to 5\% according to the adjusted Benjamini-Hochberg (abh) estimator to be obtained.

\section{Quantification of the biofilm volume via optical coherence tomography (OCT)}

To quantify the average concentration of cells and riboflavin within a biofilm or the biofilm-matrix, respectively, S. oneidensis cells were grown in M4 minimal medium under oxic conditions using $20 \mathrm{mM}$ lactate as electron donor. The cells were cultured in triplicate in a microfluidic flow-through system with straight polydimethylsiloxane (PDMS) channels and a total volume of $354 \mu \mathrm{L}$ [53]. The microfluidic systems were inoculated for $2 \mathrm{~h}$ using a culture with an $\mathrm{OD}_{600}$ of 0.08 and a flow rate of $3 \mathrm{ml} / \mathrm{h}$. During biofilm growth, the pump rate was decreased to a rate of $1 \mathrm{ml} / \mathrm{h}$. Biofilm growth was determined using OCT. After 6 days of growth, the supernatant of the biofilm was carefully removed, and the biofilm was resuspended by pipetting. Resuspended cells were counted (Neubauer chamber improved), and flavin content of the resuspended biofilm was analyzed via HPLC. Furthermore, the volume of the total biofilm was quantified using a GANYMEDE spectral domain OCT system (Thorlabs GmbH, Dachau, Germany). Biofilm volume was determined at the beginning, the middle and the end of the three PDMS chips and the mean biofilm volume was calculated.

\section{Statistical analyses}

The number of replicates used for each analysis is specified in the figure legends. Comparative transcriptomic analysis was conducted based on a false discovery ratecorrected $p$-value $(\mathrm{FDR})<0.05$ based on Wald tests.
If stated, statistical significance of qPCR experiments was determined using an unpaired $\mathrm{t}$-test with a $p$-value $<0.05$.

\section{Supplementary Information}

The online version contains supplementary material available at https://doi. org/10.1186/s13068-021-01981-3.

Additional file 1: Table S1. Strains used in this study. Table S2. Primers used in this study. Table S3. Parameters for simulation of S. oneidensis growth and riboflavin production both in batch and as continuous biofilm cultivation. Fig.S1. Impact of putrescine addition on current generation and biofilm formation on anode surfaces. Fig. S2. Impact of produced riboflavin on speC expression during growth. After 600 min 39 nM riboflavin are produced. As can be seen the relative speC expression doubles after 600 min. Fig. S3. Impact of speF deletion on current density. As can be seen the current density decreases significantly as a result of speF deletion. Fig. S4. Simulation results for a) biofilm thickness (front, middle and rear of the flow (ell), b) lactate, c) FMN and d) riboflavin concentration. e) Simulated distribution of FMN and riboflavin over the average biofilm thickness after $140 \mathrm{~h}$.

\section{Acknowledgements}

Not applicable.

\section{Authors' contributions}

ME performed the BES experiments. GS analyzed the transcriptome. ME engineered the mutant strains and performed the $\mathrm{QPCR}$ analysis. The experiments in the microfluidic chips were conducted by ME. MW helped performing the OCT measurement and the biofilm quantification. JC and JND performed the proteomic analysis. The modeling was performed by $\mathrm{HH}$. The paper was written by ME, JG, HH and KSR. All authors discussed the results and commented on the manuscript. ME, KSR, JG and HH conceived and designed the study with inputs from all authors. JG supervised the project.

\section{Funding}

Open Access funding enabled and organized by Projekt DEAL. This work was supported by a grant of the Bundesministerium für Bildung und Forschung (BMBF), No. 031B0847A.

Proteomic experiments were partly supported by the ProFI Grant (ANR-10-INBS-08-01).

\section{Availability of data and materials}

Data supporting the findings of this study are available within the article and its Supplementary Information Files and from the corresponding author upon reasonable request.

\section{Declarations}

Ethics approval and consent to participate

Not applicable.

Consent for publication

Not applicable.

\section{Competing interests}

The authors declare that they have no competing interests.

\section{Author details}

${ }^{1}$ Institute for Applied Biosciences, Department of Applied Biology, Karlsruhe Institute of Technology, Karlsruhe, Germany. ${ }^{2}$ Institute for Biological Interfaces, Karlsruhe Institute of Technology (KIT), Eggenstein-Leopoldshafen, Ger-

many. ${ }^{3}$ University Grenoble Alpes, CEA, INSERM, IRIG, BGE, Grenoble, France. ${ }^{4}$ Engler-Bunte-Institute, Water Chemistry and Water Technology, Karlsruhe Institute of Technology, Karlsruhe, Germany. ${ }^{5}$ DVGW Research Laboratories for Water Chemistry and Water Technology, Karlsruhe, Germany. 
Received: 26 March 2021 Accepted: 26 May 2021

Published online: 03 June 2021

\section{References}

1. Lovley DR, Phillips EJP. Novel mode of microbial energy metabolism: organic carbon oxidation coupled to dissimilatory reduction of iron or manganese. Appl Environ Microbiol. 1988;54:1472-80.

2. Marsili E, Baron DB, Shikhare ID, Coursolle D, Gralnick JA, Bond DR. Shewanella secretes flavins that mediate extracellular electron transfer. Proc Natl Acad Sci U S A. 2008;105:3968-73.

3. Kotloski NJ, Gralnick JA. Flavin electron shuttles dominate extracellular electron transfer by Shewanella oneidensis. MBio. 2013;4:e00553-e612.

4. Brutinel ED, Gralnick JA. Shuttling happens: Soluble flavin mediators of extracellular electron transfer in Shewanella. Appl Microbiol Biotechnol. 2012;93:41-8.

5. Okamoto A, Hashimoto K, Nealson KH, Nakamura R. Rate enhancement of bacterial extracellular electron transport involves bound flavin semiquinones. Proc Natl Acad Sci U S A. 2013;110:7856-61.

6. Okamoto A, Nakamura R, Nealson KH, Hashimoto K. Bound Flavin Mode Suggests Similar Electron-Transfer Mechanisms in Shewanella and Geobacter. ChemElectroChem. 2014;1:1808-12.

7. Xu S, Jangir Y, El-Naggar MY. Disentangling the roles of free and cytochrome-bound flavins in extracellular electron transport from Shewanella oneidensis MR-1. Electrochim Acta. 2016;198:49-55.

8. Thirumurthy MA, Jones AK. Geobacter cytochrome OmcZs binds riboflavin: implications for extracellular electron transfer. Nanotechnology. 2020:31:124001

9. Light SH, Su L, Rivera-Lugo R, Cornejo JA, Louie A, lavarone AT, AjoFranklin CM, Portnoy DA. A flavin-based extracellular electron transfer mechanism in diverse Gram-positive bacteria. Nature. 2018;562:140-4

10. Fuqua WC, Winans SC, Greenberg EP. Quorum sensing in bacteria: The LuxR-Luxl family of cell density- responsive transcriptional regulators. J Bacteriol. 1994:176(2):269-75.

11. Papenfort K, Bassler BL. Quorum sensing signal-response systems in Gram-negative bacteria. Nat Rev Microbiol. 2016;14(9):576-88.

12. Zhu J, Huang $X$, Zhang F, Feng L, Li J. Inhibition of quorum sensing, biofilm, and spoilage potential in Shewanella baltica by green tea polyphenols. J Microbiol. 2015;53:829-36.

13. de Carvalho MP, Abraham W-R. Antimicrobial and biofilm inhibiting diketopiperazines. Curr Med Chem. 2012;19:3564-77.

14. Arinda T, Philipp L-A, Rehnlund D, Edel M, Chodorski J, Stöckl M, Holtmann D, Ulber R, Gescher J, Sturm-Richter K. Addition of riboflavin-coupled magnetic beads increases current production in bioelectrochemical systems via the increased formation of anode-biofilms. Front Microbiol. 2019;10:126.

15. Bao H, Zheng Z, Yang B, Liu D, Li F, Zhang X, Li Z, Lei L. In situ monitoring of Shewanella oneidensis MR-1 biofilm growth on gold electrodes by using a Pt microelectrode. Bioelectrochemistry. 2016;109:95-100.

16. Bradshaw WJ, Davies AH, Chambers CJ, Roberts AK, Shone CC, Acharya KR. Molecular features of the sortase enzyme family. FEBS J. 2015:282:2097-114

17. Yong YC, Cai Z, Yu YY, Chen P, Jiang R, Cao B, Sun JZ, Wang JY, Song H. Increase of riboflavin biosynthesis underlies enhancement of extracellular electron transfer of Shewanella in alkaline microbial fuel cells. Bioresour Technol. 2013:130:763-8.

18. Liu T, Yu Y-Y, Deng X-P, Ng CK, Cao B, Wang J-Y, Rice SA, Kjelleberg S, Song H. Enhanced Shewanella biofilm promotes bioelectricity generation. Biotechnol Bioeng. 2015;112:2051-9.

19. Zhai DD, Li B, Sun JZ, Sun DZ, Si RW, Yong YC. Enhanced power production from microbial fuel cells with high cell density culture. Water Sci Technol. 2016;73:2176-81.

20. Lee K-J, Kim J-A, Hwang W, Park S-J, Lee K-H. Role of capsular polysaccharide (CPS) in biofilm formation and regulation of CPS production by quorum-sensing in Vibrio vulnificus. Mol Microbiol. 2013;90:841-57.

21. Niou Y-K, Wu W-L, Lin L-C, Yu M-S, Shu H-Y, Yang H-H, Lin G-H. Role of galE on biofilm formation by Thermus spp. Biochem Biophys Res Commun. 2009;390:313-8
22. Park NY, Lee JH, Kim MW, Jeong HG, Lee BC, Kim TS, Choi SH. Identification of the Vibrio vulnificus wbpP gene and evaluation of its role in virulence. Infect Immun. 2006:74:721-8.

23. Sheidy DT, Zielke RA. Analysis and expansion of the role of the Escherichia coli protein ProQ. PLoS ONE. 2013;8(10):e79656.

24. Gökçen A, Vilcinskas A, Wiesner J. Biofilm-degrading enzymes from Lysobacter gummosus. Virulence. 2014;5:378-87.

25. Esoda C, Kuehn M. Pseudomonas aeruginosa leucine aminopeptidase influences early biofilm composition and structure via vesicle-associated anti-biofilm activity. MBio. 2019;10(6):e02548-e2619.

26. Lord DM, Baran AU, Wood TK, Peti W, Page R. BdcA, a protein important for Escherichia coli biofilm dispersal, is a short-chain dehydrogenase/ reductase that binds specifically to NADPH. PLoS ONE. 2014;9(9):e105751.

27. von Canstein H, Ogawa J, Shimizu S, Lloyd JR. Secretion of flavins by Shewanella species and their role in extracellular electron transfer. Appl Environ Microbiol. 2008;74:615-23.

28. Horn H, Lackner S. 2014. Modeling of biofilm systems: a review, p. 53-76. In: Advances in biochemical engineering/biotechnology. Springer Science and Business Media Deutschland $\mathrm{GmbH}$.

29. Rajamani S, Bauer WD, Robinson JB, Farrow JM, Pesci EC, Teplitski M, Gao M, Sayre RT, Phillips DA. The vitamin riboflavin and its derivative lumichrome activate the LasR bacterial quorum-sensing receptor. Mol Plant-Microbe Interact. 2008;21:1184-92.

30. Ding Y, Peng N, Du Y, Ji L, Cao B. Disruption of putrescine biosynthesis in Shewanella oneidensis enhances biofilm cohesiveness and performance in $\mathrm{Cr}(\mathrm{VI})$ immobilization. Appl Environ Microbiol. 2014;80:1498-506.

31. Kouzuma A, Meng X-Y, Kimura N, Hashimoto K, Watanabe K. Disruption of the putative cell surface polysaccharide biosynthesis gene SO3177 in Shewanella oneidensis MR-1 enhances adhesion to electrodes and current generation in microbial fuel cells. Appl Environ Microbiol. 2010;76:4151-7.

32. Kouzuma A, Oba H, Tajima N, Hashimoto K, Watanabe K. Electrochemical selection and characterization of a high current-generating Shewanella oneidensis mutant with altered cell-surface morphology and biofilmrelated gene expression. BMC Microbiol. 2014;14:190.

33. Bursac T, Gralnick JA, Gescher J. Acetoin production via unbalanced fermentation in Shewanella oneidensis. Biotechnol Bioeng. 2017;114:1283-9.

34. Covington ED, Gelbmann CB, Kotloski NJ, Gralnick JA. An essential role for UshA in processing of extracellular flavin electron shuttles by Shewanella oneidensis. Mol Microbiol. 2010;78:519-32.

35. Poidevin L, Unal D, Belda-Palazón B, Ferrando A. Polyamines as quality control metabolites operating at the post-transcriptional level. Plants. 2019:8(4):109.

36. Nemoto N, Kurihara S, Kitahara Y, Asada K, Kato K, Suzuki H. Mechanism for regulation of the putrescine utilization pathway by the transcription factor PuuR in Escherichia coli K-12. J Bacteriol. 2012;194:3437-47.

37. Wang PY, Rao JN, Zou T, Liu L, Xiao L, Yu TX, Turner DJ, Gorospe M, Wang JY. Post-transcriptional regulation of MEK-1 by polyamines through the RNA-binding protein HuR modulating intestinal epithelial apoptosis. Biochem J. 2010:426:293-306.

38. Creuzenet C, Belanger M, WakarchukWW, Lam JS. Expression, purification, and biochemical characterization of WbpP, a new UDP-GIcNAc C4 epimerase from Pseudomonas aeruginosa serotype O6. J Biol Chem. 2000:275:19060-7.

39. Bélanger M, Burrows LL, Lam JS. Functional analysis of genes responsible for the synthesis of the B-band $\mathrm{O}$ antigen of Pseudomonas aeruginosa serotype O6 lipopolysaccharide. Microbiology. 1999;145:3505-21.

40. Miller WL, Wenzel CQ, Daniels C, Larocque S, Brisson JR, Lam JS. Biochemical characterization of WbpA, a UDP-N-acetyl-D-glucosamine 6-dehydrogenase involved in O-antigen biosynthesis in Pseudomonas aeruginosa PAO1. J Biol Chem. 2004:279:37551-8.

41. Ross DE, Brantley SL, Tien M. Kinetic characterization of OmcA and MtrC, terminal reductases involved in respiratory electron transfer for dissimilatory iron reduction in Shewanella oneidensis MR-1. Appl Environ Microbiol. 2009:75:5218-26.

42. Borloo J, Vergauwen B, De Smet L, Brigé A, Motte B, Devreese B, Van Beeumen J. A kinetic approach to the dependence of dissimilatory metal reduction by Shewanella oneidensis MR-1 on the outer membrane cytochromes c OmcA and OmcB. FEBS J. 2007;274:3728-38. 
43. Sturm G, Richter K, Doetsch A, Heide H, Louro RO, Gescher J. A dynamic periplasmic electron transfer network enables respiratory flexibility beyond a thermodynamic regulatory regime. ISME J. 2015;9:1802-11.

44. Gibson DG, Young L, Chuang R-Y, Venter JC, Hutchison CA, Smith HO. Enzymatic assembly of DNA molecules up to several hundred kilobases. Nat Methods. 2009;6:343-5.

45. Schuetz B, Schicklberger M, Kuermann J, Spormann AM, Gescher J. Periplasmic electron transfer via the c-type cytochromes MtrA and FccA of Shewanella oneidensis MR-1. Appl Environ Microbiol. 2009;75:7789-96.

46. Saltikov CW, Newman DK. Genetic identification of a respiratory arsenate reductase. Proc Natl Acad Sci U S A. 2003;100:10983-8.

47. Dolch K, Danzer J, Kabbeck T, Bierer B, Erben J, Förster AH, Maisch J, Nick P, Kerzenmacher S, Gescher J. Characterization of microbial current production as a function of microbe-electrode-interaction. Bioresour Technol. 2014;157:284-92.

48. Bradford MM. A rapid and sensitive method for the quantitation of microgram quantities of protein utilizing the principle of protein-dye binding. Anal Biochem. 1976;72:248-54.

49. Laemmli UK. Cleavage of structural proteins during the assembly of the head of bacteriophage T4. Nature. 1970;227:680-5.

50. Salvetti A, Couté Y, Epstein A, Arata L, Kraut A, Navratil V, Bouvet P, Greco A. Nuclear functions of nucleolin through global proteomics and interactomic approaches. J Proteome Res. 2016;15:1659-69.
51. Bouyssié D, Hesse A-M, Mouton-Barbosa E, Rompais M, Macron C, Carapito C, Gonzalez de Peredo A, Couté Y, Dupierris V, Burel A, Menetrey J-P, Kalaitzakis A, Poisat J, Romdhani A, Burlet-Schiltz O, Cianférani S, Garin J, Bruley C. Proline: an efficient and user-friendly software suite for largescale proteomics. Bioinformatics. 2020;36:3148-55.

52. Wieczorek S, Combes F, Lazar C, Giai Gianetto Q, Gatto L, Dorffer A, Hesse A-M, Couté Y, Ferro M, Bruley C, Burger T. DAPAR \& ProStaR: software to perform statistical analyses in quantitative discovery proteomics. Bioinformatics. 2016;33:135-6.

53. Hansen SH, Kabbeck T, Radtke CP, Krause S, Krolitzki E, Peschke T, Gasmi J, Rabe KS, Wagner M, Horn H, Hubbuch J, Gescher J, Niemeyer CM. Machine-assisted cultivation and analysis of biofilms. Sci Rep. 2019;9:1-10

\section{Publisher's Note}

Springer Nature remains neutral with regard to jurisdictional claims in published maps and institutional affiliations.
Ready to submit your research? Choose BMC and benefit from:

- fast, convenient online submission

- thorough peer review by experienced researchers in your field

- rapid publication on acceptance

- support for research data, including large and complex data types

- gold Open Access which fosters wider collaboration and increased citations

- maximum visibility for your research: over $100 \mathrm{M}$ website views per year

At BMC, research is always in progress.

Learn more biomedcentral.com/submissions 